\title{
Oxytetracycline Dynamics on Peach Leaves in Relation to Temperature, Sunlight, and Simulated Rain
}

R. S. C. Christiano, Department of Plant Pathology, University of Georgia, Athens 30602; C. C. Reilly, USDAARS Southeastern Fruit and Tree Nut Research Laboratory, Byron, GA 31008; W. P. Miller, Department of Crop and Soil Sciences, University of Georgia, Athens 30602; and H. Scherm, Department of Plant Pathology, University of Georgia, Athens 30602

\begin{abstract}
Christiano, R. S. C., Reilly, C. C., Miller, W. P., and Scherm, H. 2010. Oxytetracycline dynamics on peach leaves in relation to temperature, sunlight, and simulated rain. Plant Dis. 94:12131218.

Oxytetracycline (OTC), a member of the tetracycline antibiotics, is used as a foliar spray to control Xanthomonas arboricola pv. pruni on stone fruits and Erwinia amylovora on pome fruits. We studied the dynamics of OTC residues on attached peach (Prunus persica) leaves treated with $300 \mathrm{ppm}$ active ingredient of an agricultural OTC in relation to temperature, natural sunlight, and simulated rain. We further evaluated the potential of three ultraviolet (UV) protectants (lignin, titanium dioxide, and oxybenzone) and one sticker-extender (Nu Film-17) to prolong OTC longevity on the leaf surface. OTC residue was determined by high-pressure liquid chromatography (HPLC)-UV (C18 reversed-phase column). In controlled conditions in darkness, constant temperatures up to $40^{\circ} \mathrm{C}$ did not affect OTC degradation on leaves. In contrast, OTC residue decreased rapidly in natural sunlight in the absence of rain, declining, on average, by $43.8,77.8$, and $92.1 \%$ within 1,2 , and 4 days after application, respectively; 7 days after application, OTC levels were near the detection limit. Use of shade fabric with 10 and $40 \%$ sunlight transmittance, simulating overcast sky, reduced OTC degradation significantly but did not extend OTC persistence beyond 7 days. Areas under the OTC residue curve, summarizing OTC dynamics during the 7-day exposure period, were negatively and significantly correlated with solar radiation and UV radiation variables, but not with temperature. UV protectants and $\mathrm{Nu}$ Film-17 were ineffective in improving OTC persistence in outdoor conditions. Simulated rain at $44 \mathrm{~mm} \mathrm{~h}^{-1}$ drastically (by $67.2 \%$ ) lowered OTC residue after 2 min, and levels were near the detection limit after $60 \mathrm{~min}$ of continuous rain, regardless of whether plants were exposed to rainfall 1 or $24 \mathrm{~h}$ after OTC application. In artificial inoculation experiments with $X$. arboricola pv. pruni on attached peach leaves, OTC concentrations $\geq 50 \mathrm{ppm}$ active ingredient (corresponding to $\geq 0.06 \mu \mathrm{g}$ OTC $\mathrm{cm}^{-2}$ leaf surface) were sufficient to suppress bacterial spot development. By extrapolation from our outdoor exposure experiments, similar OTC residues following application of labeled OTC rates would be reached after less than 2 days under full sunlight, after 4 days under overcast sky, or after 2 min of a heavy rainstorm.
\end{abstract}

In the United States, oxytetracycline (OTC), a member of tetracycline antibiotics, is used to control Xanthomonas arboricola pv. pruni causing bacterial spot on stone fruits and-in areas where streptomycin resistance is prevalent-Erwinia amylovora causing fire blight on pome fruits. The compound is also used to control E. amylovora on apple in Mexico and Pseudomonas spp. and Xanthomonas spp. on vegetables in Latin America (31). Between 1999 and 2005, OTC was applied to $\sim 8 \%$ of apple, $\sim 10 \%$ of peach, and $\sim 37 \%$ of pear acreage in the United States, totaling about $10,000 \mathrm{~kg}$ of active ingredient per year in the major tree-fruit producing

Corresponding author: H. Scherm

E-mail: scherm@uga.edu

Accepted for publication 9 June 2010.

doi:10.1094/PDIS-04-10-0282

(C) 2010 The American Phytopathological Society states $(1,2,4,5)$. On bacterial spotsusceptible peach and nectarine cultivars, there are currently no alternatives to OTC use in cover sprays since copper, the only other bactericide that is consistently effective against the disease, is associated with a high risk of phytotoxicity (27). OTC deposited on the leaf surface acts as a protectant by suppressing growth of plantpathogenic bacteria prior to infection; specifically, the compound acts by inhibiting bacterial protein synthesis by binding reversibly to the ribosomes (17). Similar to other agrichemicals, OTC on the leaf surface is subject to the action of environmental forces (18), with temperature, sunlight, and rainfall believed to be the main factors responsible for affecting its residual dynamics. OTC is reported to be thermosensitive, and its stability can vary in relation to the medium, being more stable in foods than in water $(26,33,35)$.

Photolytic behavior of OTC has been verified in aquatic systems and on plants exposed to sunlight $(29,36,42)$. Ultraviolet
(UV) radiation often is the principal fraction of the solar spectrum implicated in the degradation of active ingredients of agrichemicals. In some cases, the use of UV protectants has been advocated to extend the persistence of photosensitive active ingredients, especially those based on biocontrol agents, on plant surfaces $(6,14,22$, $23,30,40)$. UV protectants are compounds that protect the target from UV radiation by absorbing it (e.g., oxybenzone), reflecting it (e.g., titanium dioxide), or a combination of both (37).

Rainwater and the splashing associated with rain drops can readily dissolve and wash agrichemical residues from leaf surfaces. In many studies, rain simulators have been used to determine the impact of the amount and/or intensity of rainfall on persistence of pesticide active ingredients $(15,43)$.

Apart from one recently published study on tomato (29) and an unpublished thesis on peach (7), there is limited information on the dynamics of agricultural OTC on plant surfaces. To better understand the residue dynamics of OTC on peach foliage, we monitored OTC concentrations on leaves in relation to temperature, sunlight, and rainfall in controlled and semicontrolled conditions (on potted plants outdoors or under a rain simulator). Additionally, we evaluated the potential of several UV protectants to enhance persistence of OTC on the foliage during exposure to natural sunlight.

\section{MATERIALS AND METHODS}

OTC application and sampling. All experiments were carried out at the Athens campus of the University of Georgia. Greenhouse-grown peach seedlings (Prunus persica cv. Lovell) in 2.6-liter plastic containers, approximately $1 \mathrm{~m}$ in height, were treated with an aqueous suspension of an agricultural OTC (Mycoshield, $17 \%$ OTC formulated as an oxytetracycline-calcium complex; NuFarm Americas, Burr Ridge, IL) at 300 ppm active ingredient (a.i.) by spraying both sides of the leaves to near runoff using an atomizer. Leaf samples for OTC residue analysis were collected just prior to application (negative control) and at discrete intervals after application as described for the various experiments below. Individual experimental units from which samples 
were collected consisted of two plants per treatment.

At each sampling date, five fully expanded leaves (exposed at the time of OTC application) were removed from the middle to upper canopy of the two peach seedlings. Ten disks were punched from the midcenter of these leaves (two disks per leaf) using a $133-\mathrm{mm}^{2}$ cork borer. Disks were transferred to 50-ml centrifuge tubes containing $5 \mathrm{ml}$ of McIIvaine bufferEDTA, pH 4.0 (3), and vortexed at 2,500 $\min ^{-1}$ for $10 \mathrm{~min}$. The wash suspension from each sample was filtered using a 0.2$\mu \mathrm{m}$ nylon syringe filter and stored at $5^{\circ} \mathrm{C}$ in the dark for a maximum of 2 weeks until analysis by high-pressure liquid chromatography (HPLC).

In a preliminary experiment, the amount of OTC in wash buffer obtained as described above was compared with OTC recovered from leaf disks macerated in McIIvaine buffer-EDTA, whereby the macerate was centrifuged at 4,500 $\mathrm{min}^{-1}$ for $10 \mathrm{~min}$, and the supernatant was filtered with a $0.2-\mu \mathrm{m}$ nylon syringe filter and used for HPLC analysis.

HPLC analysis. Samples were analyzed with a Thermo Scientific SpectraSYSTEM HPLC unit equipped with a SCM1000 membrane degasser, a P2000 gradient pump, a UV1000 variable-wavelength detector set at $354 \mathrm{~nm}$, and a SN4000 interface with ChromQuest 4.1 data system (Thermo Fisher Scientific, Waltham, MA). The analytical column used was an Alltech Alltima C18, 5- $\mu \mathrm{m}, 4.6 \times 150 \mathrm{~mm}$ reversed-phase column (Alltech, Deerfield, IL) at $35.0^{\circ} \mathrm{C}$. The mobile phase was $75: 25$ water:acetonitrile containing $0.1 \%$ trifluoroacetic acid in water at a flow rate of $1 \mathrm{ml}$ $\min ^{-1}$. Sample aliquots of $20 \mu \mathrm{l}$ were injected, and total run time per sample was $10 \mathrm{~min}$. OTC recovery was $99.9 \%$, and the detection limit was $50 \mathrm{ppb}$. Residue levels were quantified based on a standard curve obtained by amending wash buffer from untreated leaves with technical OTC (Sigma-Aldrich, St. Louis, MO) at eight concentrations ranging from 0.03 to 8.0 ppm. In most experiments, OTC residue levels measured over time were expressed as a percentage of the OTC residue measured immediately after spray application (day 0).

Thermostability. The effect of temperature on OTC residue levels on peach leaves was investigated in controlled conditions. After spray-application of OTC, peach seedlings were transferred to dark growth chambers set at $25,30,35$, and $40^{\circ} \mathrm{C}$ $\left( \pm 1^{\circ} \mathrm{C}\right)$. Leaf samples were collected 0,1 , 2, 3, 4, and 7 days after OTC application. There were two replicates of two peach seedlings each per temperature treatment, and four independent experimental runs were carried out over time. Linear regression analysis was applied to means of the four experimental runs to determine whether there was a significant effect of time (days after application) on OTC residue levels for each temperature.

Photosensitivity. Two replicates of two peach seedlings each were treated with OTC and exposed to natural sunlight outdoors during periods when rain was absent. Leaf samples were collected $0,1,2$, 3,4 , and 7 days after OTC application, and OTC residue dynamics over time were summarized as standardized area under the OTC residue curve during the 7-day exposure period. Standardized areas under the curve (having units of percent) were calculated by trapezoidal integration followed by division by the exposure time (28). Eight independent experimental runs were conducted between February and October 2008 (Fig. 1). Hourly weather data (air temperature, solar radiation, and UV radiation index on a scale from 0 to $>11$ ) were obtained from the Climatology Research Laboratory on the University of Georgia campus. Averages and maxima of temperature and radiation variables during defined exposure periods ( 0 to 2 days, 0 to 4 days, and 0 to 7 days after application) were calculated and related to the area under the OTC residue curve using correlation analysis. During the experimental runs in June, July, September, and October, additional peach seedlings were treated with OTC and exposed outdoors in cages $(1.5 \times$ $1.5 \times 1.5 \mathrm{~m})$ covered with shade fabric (Gale Pacific, Altamonte Springs, FL) having 10 and $40 \%$ sunlight transmittance (i.e., 90 and $60 \%$ shade, respectively). Percent reduction of solar radiation and UV radiation by the shade fabric was verified by spot measurements with a pyranometer (Li-Cor, Lincoln, NE) and a UV radiometer (Eppley, Newport, RI), respectively. Areas under the OTC residue curve during the 0 - to 7-day exposure period were calculated for each of the treatments (100, 40, and 10\% sunlight transmittance). Treatment means were compared with analysis of variance (ANOVA) followed by means separation with Fisher's protected LSD test, using the four experimental runs as replicates (blocks). Data from the four runs with shading were also included in the correlation analysis between area under the OTC residue curve and weather variables (described above); in this analysis, solar and UV radiation values were multiplied with the corresponding shade fabric transmittance (10 or $40 \%$ ) to calculate averages and maxima.

UV protectants. Four different UV protectants and one spreader-extender were applied together with OTC to determine their effect on OTC residue dynamics: lignin (lignin alkali kraft; Sigma-Aldrich), titanium dioxide (titanium (IV) oxide; Sigma-Aldrich), oxybenzone (2-hydroxy4-methoxybenzophenone; Sigma-Aldrich), and Nu Film-17 (di-1-p-menthene; Miller, Hanover, PA). Two replicates, each consisting of two peach seedlings, were sprayed with OTC plus $2 \%$ of each UV protectant, and treated plants were exposed to natural sunlight during the May, June, July, September, and October exposure experiments. Control seedlings were sprayed with OTC only. Leaf samples for OTC residue analysis were collected 0,1 , 2, 3, 4, and 7 days after treatment. Areas under the OTC residue curve were calculated and compared with ANOVA followed by means separation with Fisher's protected LSD test, using the five experimental runs as replicates (blocks).

Rainfastness. Rain was simulated in an indoor environment (fluorescent light, $25 \pm$ $2^{\circ} \mathrm{C}$ ) using the rainfall simulator described by Miller (32). The water supply was a municipal source with low dissolved ion content (electrical conductivity $\sim 0.15 \mathrm{mS}$ $\mathrm{cm}^{-1}$ ). Rainfall intensity was set at $44 \mathrm{~mm}$ $\mathrm{h}^{-1}$, simulating a rainstorm with 1 -year return frequency in the southeastern United States (19). Groups of 10 peach seedlings each were subjected to simulated rain 1 and $24 \mathrm{~h}$ after application of OTC. Leaf samples (two replicates of five leaves each, one leaf per seedling) for residue analysis were collected after $0,2,5,10$, 30 , and $60 \mathrm{~min}$ of rainfall duration (corresponding to $0,1.5,3.7,7.3,22$, and $44 \mathrm{~mm}$ of cumulative rain). Four independent experimental runs were conducted, and means of OTC residue levels across runs were plotted against cumulative rainfall.

OTC residue needed to control $X$. arboricola pv. pruni. To determine the minimum level of OTC needed to suppress $X$. arboricola pv. pruni on peach foliage, five seedlings were sprayed with Mycoshield suspensions of $0,12.5,25,50$, and $100 \mathrm{ppm}$ a.i. OTC in the greenhouse in the late afternoon. Early the next morning, the plants were spray-inoculated to near runoff with a suspension of the pathogen (isolate Xap88-GA) at $10^{7} \mathrm{CFU} \mathrm{ml}^{-1}$ and covered with plastic bags for $48 \mathrm{~h}$ to create a moist chamber. The bacterial suspension for inoculation had been made from a 48h-old culture of the pathogen grown on nutrient agar, diluted in sterile deionized water, and quantified by spectrophotometer. Disease severity (percent leaf area affected) was measured on four symptomatic leaves per plant at 40 days postinoculation using the image analysis software QUANT 1.0 (41). Four independent experimental runs were conducted, and mean disease severity levels across runs were calculated and plotted against OTC concentration to determine at what concentration disease control would no longer be effective.

\section{RESULTS}

The amount of OTC in leaf disk wash buffer following spray-application of 300 ppm a.i. OTC (averaging $0.34 \pm 0.10$ [SD] $\mu \mathrm{g} \mathrm{cm}^{-2}$ calculated based on both sides of the leaf surface, $n=120$ ) was similar to that obtained from entire macerated leaf disks in preliminary tests (data not 
shown); thus, all OTC extractions were done using the leaf disk wash approach described above.

In the thermostability experiments in darkness, some variability in OTC residue levels over time was noted (Fig. 2). However, the slope estimate of the linear regression of residue versus time (days after OTC application) was not significantly different from zero for any of the temperatures tested $(P=0.09,0.34,0.16$, and 0.92 for $25,30,35$, and $40^{\circ} \mathrm{C}$, respectively). Thus, temperature in the range of 25 to $40^{\circ} \mathrm{C}$ did not affect degradation of OTC in the absence of light.

In the photosensitivity experiments, OTC residue decreased rapidly to near the detection limit during 7 days of exposure to natural sunlight (Fig. 3A). The rate of degradation of OTC varied in relation to sunlight intensity. Under full sunlight, OTC residue dropped by $43.8 \%$ within the first day after application, and only $7.9 \%$ of the initial residue remained on the fourth day after application. Under reduced sunlight exposure (10 and $40 \%$ transmittance), OTC residues decreased by 19.4 to $29.2 \%$ within the first day and by 59.4 to $64.1 \%$ on the third day after application, dropping to $3.3 \%$ of the initial residue on the seventh day. When residue dynamics over the 7-day exposure period were summarized as area under the OTC residue curve, values were significantly lower after exposure to full sunlight than under reduced sunlight with 10 or $40 \%$ transmit- tance (Fig. 3B). Nevertheless, shading was insufficient to prolong OTC residue longevity beyond 7 days.

Variations in the area under the OTC residue curve during the eight experimental runs (which included the four runs with shading treatments) was significantly $(P<$ 0.05 ) and negatively correlated with solar and UV radiation (Table 1). Association with sunlight was significant regardless of whether radiation variables were summarized for 0 to 2, 0 to 4 , or 0 to 7 days after application. In contrast, there was no significant association with temperature variables, supporting the growth chamber results presented above.

None of the UV protectants evaluated increased OTC retention significantly compared with the untreated check (Fig. 4). Regardless of the treatment, OTC residue curves dropped exponentially, with the steepest decreases during the first 2 days and final OTC levels near the detection limit after 7 days (Fig. 4A). The total area under the OTC residue curve was significantly lower for the titanium dioxide treatment than in the control without UV protectant application (Fig. 4B), indicating that this compound had a negative effect on OTC residue levels over time.

In the rainfastness experiments, OTC removal by simulated rain was very similar regardless of whether rain was applied 1 or $24 \mathrm{~h}$ after OTC application (Fig. 5). About two-thirds of the OTC was removed after the first $1.5 \mathrm{~mm}$ of rain, with lower rates of removal as the cumulative amount of rain increased. After 60 min of continuous rain (44 $\mathrm{mm}$ of cumulative of rainfall), only $5.7 \%$ of OTC residue remained on the leaf surface.

As in previous artificial inoculation experiments with $X$. arboricola pv. pruni (10), disease severity was low even in the absence of OTC treatment (Fig. 6). Nevertheless, application of increasing concentrations of OTC resulted in highly reproducible reductions in disease severity across the four experimental runs. Disease severity dropped rapidly as OTC concentration increased between 0 and $50 \mathrm{ppm}$, whereas increasing the concentration from 50 to $100 \mathrm{ppm}$ did not result in a markedly improved level of disease suppression. Thus, the minimum OTC concentration providing satisfactory suppression of bacterial spot was $\sim 50 \mathrm{ppm}$, corresponding to $0.06 \mu \mathrm{g}$ of OTC per $\mathrm{cm}^{2}$ of leaf surface.

\section{DISCUSSION}

Virtually all of the applied OTC appears to remain on the leaf surface and does not enter systemically into leaf tissue, as documented in preliminary tests in which the amount of OTC recovered from treated leaves was similar when wash buffer was analyzed relative to when macerated leaf disks were tested. This is further supported by the observation that there was no significant decrease over a 7-day period of OTC on the leaf surface in darkness in our

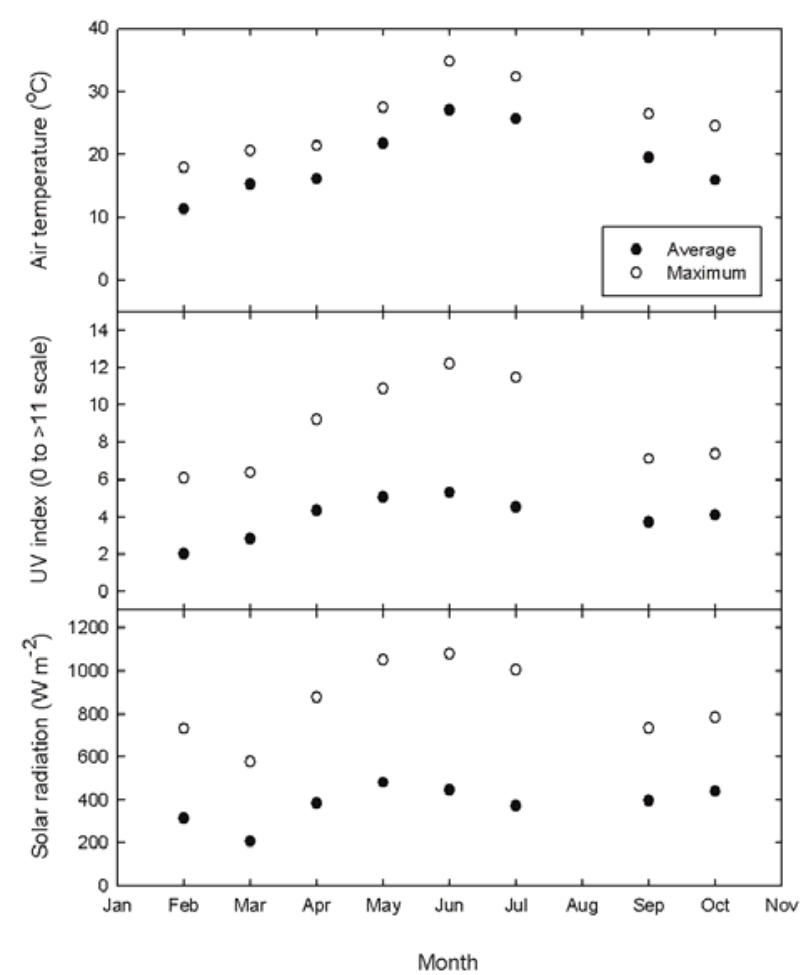

Fig. 1. Meteorological conditions during eight weekly periods when oxytetracycline-treated peach seedlings were exposed to natural sunlight outdoors between February and October 2008. Averages of radiation variables were calculated during daytime hours only. No rain occurred during these exposure periods.

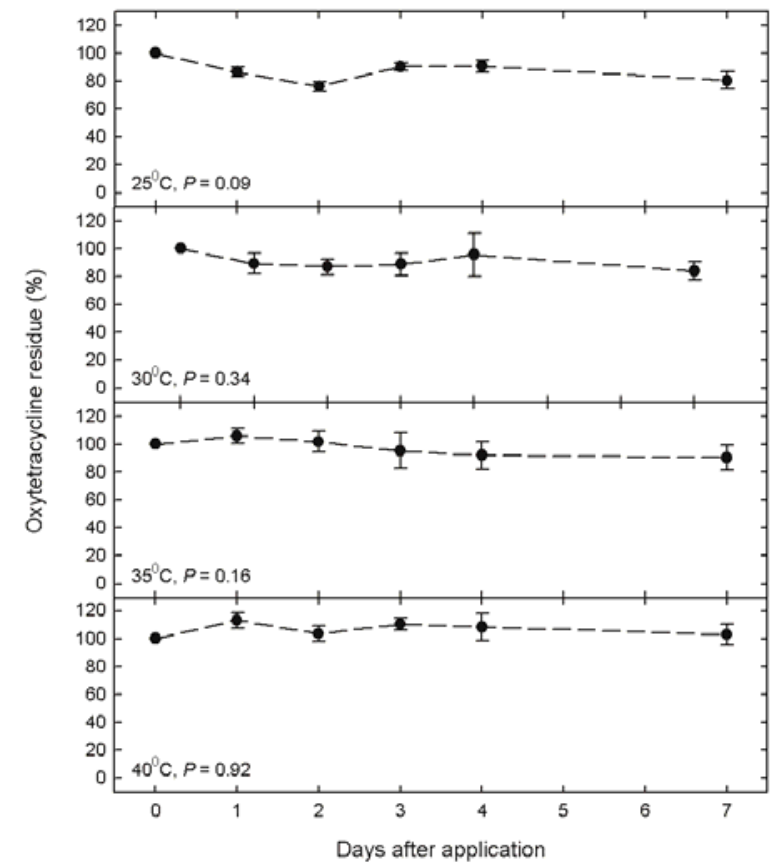

Fig. 2. Effect of different constant temperatures on oxytetracycline residues on leaves of treated peach seedlings maintained in growth chambers in darkness for 7 days after application. Oxytetracycline residues are expressed as a percentage of the initial residue level measured immediately after application (day 0 ), which were typically $0.34 \pm 0.10$ (SD) $\mu \mathrm{g} \mathrm{cm}^{-2}$ leaf surface. Values represent means and standard errors of four independent experimental runs. $P$ values indicate significance level of the slope estimate of the linear regression of residue level vs. time (days after application). 
temperature experiments, again showing a lack of uptake into plant tissue. Reports of systemic in planta movement of OTC in the literature $(13,24)$ refer to systemic transport in the vascular system following trunk injections and do not appear to be relevant to systemic uptake by the foliage following spray application.

OTC has been shown to be thermosensitive at temperatures above $60^{\circ} \mathrm{C}(8,34)$. For temperatures more relevant to field conditions (25 to $40^{\circ} \mathrm{C}$ ), however, our controlled-environment experiments showed no significant OTC degradation on the leaf surface during a 1-week period when the plants were maintained in darkness. Thus, temperature can be excluded as a factor directly affecting OTC dynamics in the field. This is supported by the lack of a significant correlation between average or maximum temperature and the area under the OTC residue curve in our outdoor experiments.

In the outdoor experiments, OTC residues dropped rapidly (by $43.8 \%$ ) within 1 day after application and by $\sim 100 \%$ after 1 week. In the absence of rain and without a direct temperature effect, sunlight is the
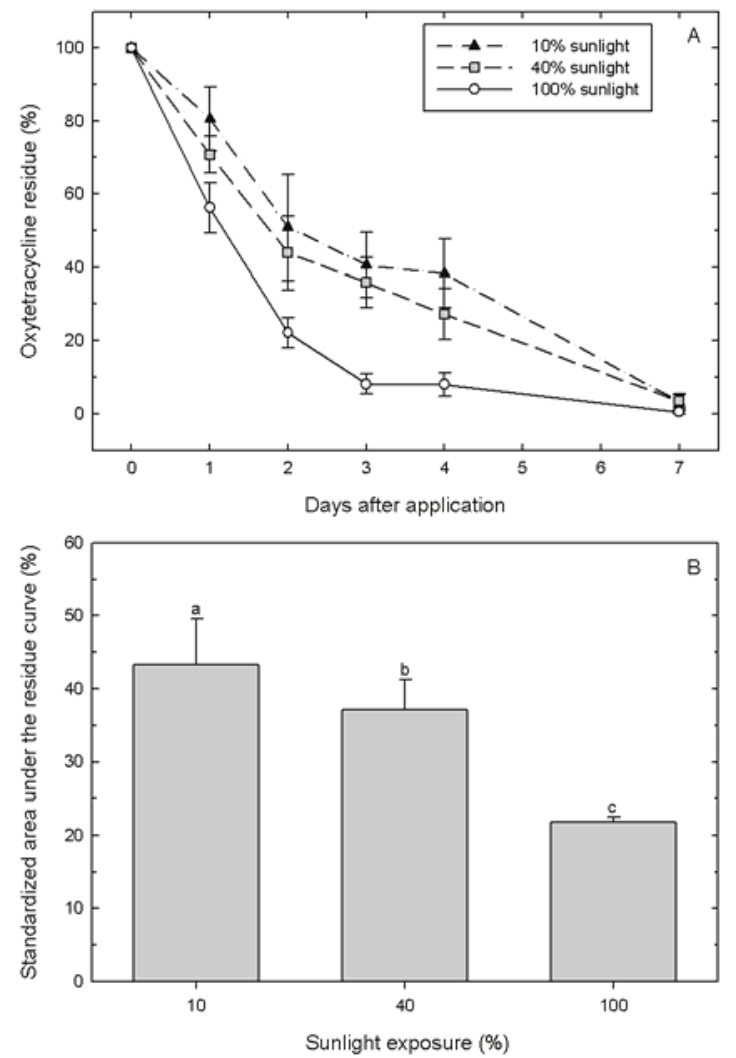

Fig. 3. Effect of sunlight exposure on $\mathbf{A}$, oxytetracycline residues and $\mathbf{B}$, area under the oxytetracycline residue curve on leaves of treated peach seedlings exposed outdoors for 7 days after application. Treatments with 10 and $40 \%$ sunlight exposure were obtained by placing seedlings under shade fabric with the corresponding transmittance values. Oxytetracycline residues are expressed as a percentage of the initial residue level measured immediately after application (day 0), which were typically $0.34 \pm$ 0.10 (SD) $\mu \mathrm{g} \mathrm{cm}^{-2}$ leaf surface. Values represent means and standard errors of four independent experimental runs conducted during June, July, September, and October 2008. Means followed by the same letter are not significantly different according to Fisher's protected LSD test.

most likely factor affecting the rate of OTC degradation. In absence of light, OTC is retained on the leaf surface as observed in our controlled-environment experiments. Indeed, Halling-Sorensen et al. (18) detected OTC residue for more than 100 days in a water-soil system in the absence of light. When sunlight was partially blocked with shade fabric in our experiments, OTC retention was improved, increasing the area under the OTC residue curve by up to twofold. A major role of sunlight in reducing OTC residues outdoors is also suggested by our correlation analyses, where the area under the OTC residue curve was consistently and significantly affected by sunlight-related variables. Rapid degradation of OTC was also observed by Maia et al. (29) on tomato fruit in the field, where residue levels dropped by $\sim 30 \%$ after 1 day and by close to $100 \% 6$ days postapplication. Earlier studies $(7,25)$ suggested greater OTC longevity on plant surfaces ( $\sim 10$ days), although differences in the methodology to detected OTC residue between these studies (indirectly via bioassay) and the more recent studies (by HPLC analysis) mean that the results are not directly comparable.

Our study was not designed to determine specifically which fraction(s) of the sunlight spectrum is responsible for the observed degradation of OTC. In our correlation analyses, both total solar radiation and UV index correlated similarly with the area under the OTC residue curve, having correlation coefficients around 0.6. In a study documenting the fate of OTC in water, Verma et al. (42) showed that blocking UV with glass filters reduced OTC degradation by only one-third, meaning that other fractions of the sunlight spectrum are also important, or at least that UV is not the sole factor.

Application of UV protectants has been shown to enhance the persistence of UVsensitive agents in laboratory conditions, but the beneficial effect of such amendments in field conditions has been less convincing $(6,14,30,40)$. In our study, UV protectants were unable to enhance OTC longevity on the leaf surface. Among the materials tested, oxybenzone absorbs

Table 1. Pearson's correlation coefficients (with $P$ values in parentheses) for associations between selected environmental variables and the area under the oxytetracycline residue curve on leaves of treated peach seedlings exposed outdoors between February and October 2008

\begin{tabular}{|c|c|c|c|c|c|c|}
\hline \multirow[b]{3}{*}{ Exposure period $^{b}$} & \multicolumn{6}{|c|}{ Environmental variable ${ }^{a}$} \\
\hline & \multicolumn{2}{|c|}{ Temperature } & \multicolumn{2}{|c|}{ Solar radiation } & \multicolumn{2}{|c|}{ Ultraviolet radiation } \\
\hline & Average & Maximum & Average & Maximum & Average & Maximum \\
\hline Days 0-2 & $\begin{array}{c}0.055 \\
(0.897)\end{array}$ & $\begin{array}{c}0.032 \\
(0.940)\end{array}$ & $\begin{array}{c}-0.578 \\
(0.019)\end{array}$ & $\begin{array}{c}-0.641 \\
(0.008)\end{array}$ & $\begin{array}{c}-0.588 \\
(0.017)\end{array}$ & $\begin{array}{c}-0.659 \\
(0.005)\end{array}$ \\
\hline Days 0-4 & $\begin{array}{r}-0.019 \\
0.964\end{array}$ & $\begin{array}{r}-0.057 \\
0.894\end{array}$ & $\begin{array}{c}-0.623 \\
(0.010)\end{array}$ & $\begin{array}{c}-0.669 \\
(0.005)\end{array}$ & $\begin{array}{c}-0.641 \\
(0.008)\end{array}$ & $\begin{array}{c}-0.683 \\
(0.004)\end{array}$ \\
\hline Days 0-7 & $\begin{array}{c}-0.027 \\
(0.949)\end{array}$ & $\begin{array}{c}-0.107 \\
(0.801)\end{array}$ & $\begin{array}{c}-0.659 \\
(0.006)\end{array}$ & $\begin{array}{c}-0.697 \\
(0.003)\end{array}$ & $\begin{array}{c}-0.648 \\
(0.007)\end{array}$ & $\begin{array}{c}-0.680 \\
(0.004)\end{array}$ \\
\hline
\end{tabular}

${ }^{a} n=16$ for solar and ultraviolet radiation and $n=8$ for temperature variables.

${ }^{\mathrm{b}}$ Areas under the oxytetracycline progress curve were calculated for the entire 7-day exposure period, whereas averages and maxima of weather variables were summarized for the periods indicated, where day 0 represents the day of oxytetracycline application. 
within the full UV spectrum, whereas lignin adsorbs visible wavelengths and serves as a physical barrier by forming multiple protective layers on the leaf surface that can stabilize and improve the activity of pesticides (12). Titanium dioxide reflects UV light, although in the presence of water and light it can catalyze the production of hydrogen peroxide, a powerful oxidative agent (20). This latter property may explain the significantly enhanced OTC degradation observed after titanium dioxide application in our experiments. Nu Film17 is a spreader-extender and therefore acts more broadly than the other compounds included in this study; nevertheless, it, too, was unable to extend OTC longevity on the leaf surface.

Simulated rainfall readily removed OTC from the leaf surface, regardless of whether the antibiotic had been applied 1 or $24 \mathrm{~h}$ before the onset of rain. The rain intensity used in our experiments was representative of heavy storms that occur regularly in the southeastern United States $(16,19,39)$. At this intensity, 1.5 and 5 min of rain were sufficient to remove approximately 60 and $80 \%$ of OTC residue, respectively. Bernstein (7) also observed rapid wash-off of OTC from peach leaves (reduction by $82 \%$ after $5 \mathrm{~mm}$ of rain). In addition, Keil and Weaver (25) suggested reapplication of OTC if rainfall occurred. Retention of active ingredients deposited on leaves is also influenced by the micromorphology and chemical composition of the surface, as well as the amount and composition of leaf wax $(9,21)$, which may differ between greenhouse- and fieldgrown plants. Nevertheless, it is clear from our study that OTC has a low retention capacity in response to rain, even after 24 $\mathrm{h}$ on the leaf surface.

Our inoculation experiments showed good bacterial spot suppression when OTC was applied at a concentration at or above $50 \mathrm{ppm}$ a.i. This is consistent with data presented by Daines (11), who observed significant bacterial suppression above 60 ppm a.i. in the field. Assuming OTC is applied at the labeled rate of $150 \mathrm{ppm}$ a.i., this implies that about two-thirds of the initial residue can be removed (by photolysis or wash-off) before disease control would break down. In natural sunlight without rain, this level of OTC degradation is reached less than 2 days after application (cf. Fig. 2). Cloud cover (i.e., reduction of sunlight intensity) can prolong the effective period for another 2 days, giving a total of 4 days of protection (cf. Fig. 2). In contrast, 2 min of a storm shower are sufficient to remove two-thirds of the applied OTC, resulting in concentrations of the antibiotic too low to provide sufficient protection against $X$. arboricola pv. pruni.

The main economic damage caused by bacterial spot is due to fruit infections, which can result in deep-pitted lesions, extensive gumming, and increased fruit susceptibility to fungal pre- and postharvest rots. The pronounced pubescence of peach fruit may improve OTC retention relative to that of leaves, and additional research is needed to compare the dynamics of the antibiotic on the two tissue types exposed to identical environmental conditions. Still, given the critical role of leaf infections in the carry-over of the pathogen from its overwintering sites in twig cankers, buds, and leaf scars $(38,44)$ to the fruit, strategies to increase the efficacy of OTC on the foliage need to be investigated further. In light of the ineffectiveness of conventional UV protectants in prolonging OTC longevity on peach leaves, other
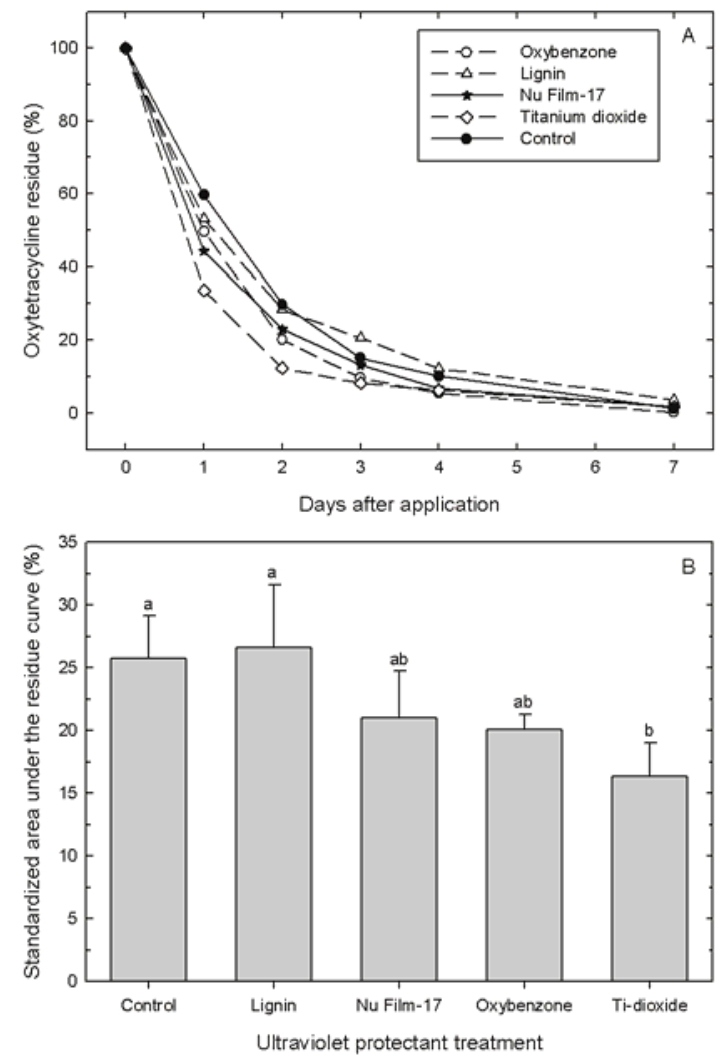

Fig. 4. Effect of three ultraviolet protectants (oxybenzone, lignin, and titanium dioxide) and a spreader-extender (Nu Film-17) on A, oxytetracycline residues and $\mathbf{B}$, area under the oxytetracycline residue curve on leaves of treated peach seedlings exposed outdoors for 7 days after application. Oxytetracycline residues are expressed as a percentage of the initial residue level measured immediately after application (day 0 ), which were typically $0.34 \pm 0.10$ (SD) $\mu \mathrm{g} \mathrm{cm}^{-2}$ leaf surface. Values represent means and standard errors of five independent experimental runs conducted in May, June, July, September, and October 2008. Means followed by the same letter are not significantly different according to Fisher's protected LSD test.

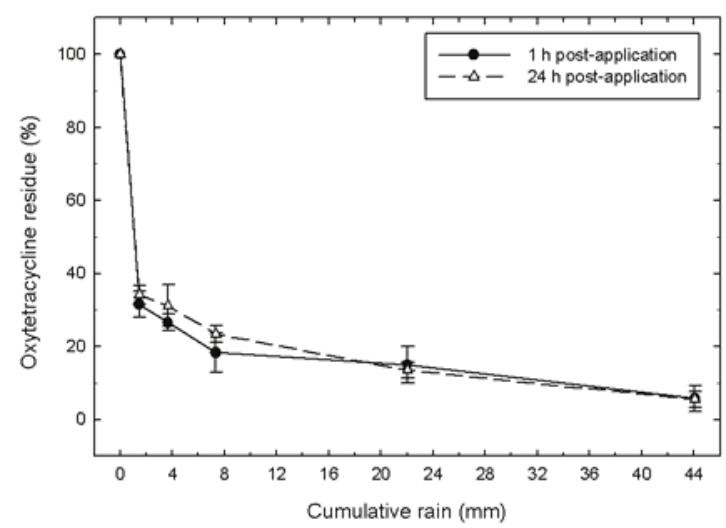

Fig. 5. Effect of rainfall (applied at an intensity of $44 \mathrm{~mm} \mathrm{~h}^{-1}$ ) on oxytetracycline residues on leaves of treated peach seedlings exposed under a rain simulator for up to $1 \mathrm{~h}$. Treated seedlings were exposed to rain 1 or $24 \mathrm{~h}$ after oxytetracycline application. Oxytetracycline residues are expressed as a percentage of the initial residue level measured immediately after application $(0 \mathrm{~mm}$ of rain), which were typically $0.34 \pm 0.10$ (SD) $\mu \mathrm{g} \mathrm{cm}{ }^{-2}$ leaf surface. Values represent means and standard errors of four independent experimental runs. 


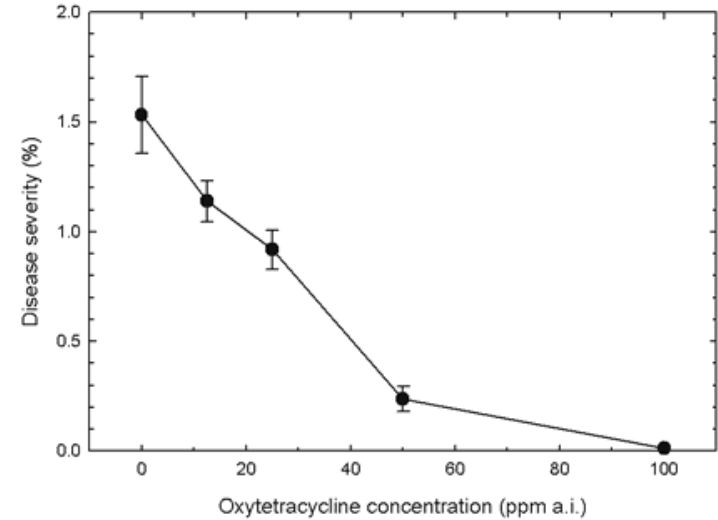

Fig. 6. Effect of spray-applied oxytetracycline concentration on the severity of bacterial spot disease (caused by Xanthomonas arboricola pv. pruni) on leaves of peach seedlings in the greenhouse. Values represent means and standard errors of four independent experimental runs. a.i. $=$ active ingredient.

methods to extend the persistence of OTC residues need to be explored, including improved adjuvants to protect the compound from sunlight damage and wash-off.

\section{ACKNOWLEDGMENTS}

Funded in part by USDA-CSREES awards 2004-04014 (Risk Avoidance and Mitigation Program) and 2007-03620 (Southern Region IPM Program).

\section{LITERATURE CITED}

1. Anonymous. 2000. Agricultural Chemical Usage 1999 Fruit and Nut Summary. Published online. U.S. Dep. Agric. Nat. Agric. Stat. Serv.

2. Anonymous. 2002. Agricultural Chemical Usage 2001 Fruit Summary. Published online. U.S. Dep. Agric. Nat. Agric. Stat. Serv.

3. Anonymous. 2003. Qualitative Identification of Tetracyclines in Tissues. Published online. U.S. Dep. Agric. Food Safety Inspection Serv.

4. Anonymous. 2004. Agricultural Chemical Usage 2003 Fruit Summary. Published online. U.S. Dep. Agric. Nat. Agric. Stat. Serv.

5. Anonymous. 2006. Agricultural Chemical Usage 2005 Fruit Summary. Published online. U.S. Dep. Agric. Nat. Agric. Stat. Serv.

6. Arthurs, S. P., Lacey, L. A., and Behle, R. W. 2006. Evaluation of spray-dried lignin-based formulations and adjuvants as solar protectants for the granulovirus of the codling moth, $\mathrm{Cy}$ dia pomonella (L). J. Invertebrate Pathol. 93:88-95.

7. Bernstein, B. 1991. Persistence of oxytetracycline residues on peach (Prunus persica (L.) Batsch) leaves following irrigation, sunlight or dew. M.S. thesis. Clemson University, Clemson, SC.

8. Berruga, I., Zorraquino, M. A., Beltran, M. C., Althaus, R. L., and Molina, M. P. 2005. Effect of heat treatments on the antimicrobial activity of beta-lactams and tetracyclines in milk. Published online. XIII Congreso Internacional de la Federacion Mediterranea de Sanidad y Produccion de Rumiantes, Bari, Italy.

9. Bringe, K., Hunsche, M., Schmitz-Eiberger, M., and Noga, G. 2005. Significance of apple leaf surface characteristics for retention and rainfastness of the fungicide mancozeb. Pages 507-510 in: Proc. Crop Sci. Technol. 2005. British Crop Protection Council, Glasgow.

10. Civerolo, E. L. 1975. Quantitative aspects of pathogenesis of Xanthomonas pruni in peach leaves. Phytopathology 65:258-264.

11. Daines, R. H. 1967. Control of bacterial spot of peach in New Jersey. Plant Dis. Rep. 51:349-351.

12. DelliColli, H. T. 1980. Pine kraft lignin as a pesticide delivery system. Pages 225-234 in:
Controlled Release Technologies: Methods, Theory and Applications, Vol. II. A. F. Kydonieus, ed. CRC Press, Boca Raton, FL.

13. Dunegan, J. C., Wilson, R. A., and Morris, W. T. 1953. Effects of terramycin on peach trees affected with bacterial spot. Plant Dis. Rep. 37:604-605.

14. Farrar, R. R., Jr., Shapiro, M., and Javaid, I. 2003. Photostabilized titanium dioxide and a fluorescent brightener as adjuvants for a nucleopolyhedrovirus. BioControl 48:543-560.

15. Fifea, J. P., and Nokes, S. E. 2002. Evaluation of the effect of rainfall intensity and duration on the persistence of chlorothalonil on processing tomato foliage. Crop Prot. 21:733-740.

16. Frauenfeld, B., and Truman, C. C. 2004. Variable rainfall intensity effects on runoff and interrill erosion from two Coastal Plain ultisols in Georgia. Soil Sci. 169:143-154.

17. Goodman, R. N. 1959. The influence of antibiotics on plants and plant disease control. Pages 322-448 in: Antibiotics: Their Chemistry and Non-Medical Uses. H.S. Goldberg, ed. van Nostrand, Princeton, NJ.

18. Halling-Sorensen, B., Sengeløv, G., Ingerslev, F., and Jensen, L. B. 2003. Reduced antimicrobial potencies of oxytetracycline, tylosin, sulfadiazine, streptomycin, ciprofloxacin, and olaquindox due to environmental processes. Arch. Environ. Contam. Toxicol. 44:7-16.

19. Hershfield, D. M. 1961. Rainfall frequency atlas of the United States. Weather Bureau Tech. Pap. 40. U.S. Department of Commerce, Washington, DC.

20. Hoffman, M. R., Martin, S. T., Choi, W., and Bahnemann, D. W. 1995. Environmental applications of semiconductor photocatalysis. Chem. Rev. 95:69-96.

21. Hunsche, M., Bringe, K., Schmitz-Eiberger, M., and Noga, G. 2006. Leaf surface characteristics of apple seedlings, bean seedlings and kohlrabi plants and their impact on the retention and rainfastness of mancozeb. Pest Manag. Sci. 62:839-847.

22. Hunt, T., Moore, D., Higgins, P. M., and Prior, C. 1994. Effect of sunscreen, irradiance and resting periods on the germination of Metarhizium flavoviride conidia. Entomophaga 39:313-322.

23. Inglis, G. D., Goettel, M. S., and Johnson, D. 1995. Influence of ultraviolet light protectants on persistence of the entomopathogenic fungus, Beauveria bassiana. Biol. Control 5:581-590.

24. Keil, H. L. 1979. Control of bacterial spot (caused by Xanthomonas pruni) in apricot trees by trunk infusion with oxytetracycline. Plant Dis. Rep. 63:407-409.

25. Keil, H. L., and Weaver, L. D. 1970. Grower trials with oxytetracycline for control of peach bacterial spot in Maryland. Plant Dis. Rep.
54:208-211

26. Kitts, D. D., Yu, C. W. Y., Burt, R. G., and McErlane, K. 1992. Oxytetracycline degradation in thermally processed farm salmon. J. Agric. Food Chem. 140:1977-1981.

27. Lalancette, N., and McFarland, K. A. 2007. Phytotoxicity of copper-based bactericides to peach and nectarine. Plant Dis. 91:1122-1130.

28. Madden, L. V., Hughes, G., and van den Bosch, F. 2007. The Study of Plant Disease Epidemics. American Phytopathological Society, St. Paul, MN.

29. Maia, P. P., Silva, E. C., Rath, S., and Reyes, F. G. R. 2009. Residue content of oxytetracycline applied on tomatoes grown in open field and greenhouse. Food Control 20:11-16

30. Mcguire, M. R., Tamez-Guerra, P., Behle, R. W., and Streett, D. A. 2001. Comparative field stability of selected entomopathogenic virus formulations. J. Econ. Entomol. 94:1037-1044.

31. McManus, P. S., Stockwell, V. O., Sundin, G. W., and Jones A. L. 2002. Antibiotic use in plant agriculture. Annu. Rev. Phytopathol. 40:443-465.

32. Miller, W. P. 1987. A solenoid-operated, variable intensity rainfall simulator. Soil Sci. Am. J. 51:832-834

33. Moats, W. A. 1988. Inactivation of antibiotics by heating in foods and other substrates: A review. J. Food Prot. 51:491-497.

34. Moats, W. A. 1999. The effect of processing on veterinary residues in foods. Pages 233-241 in Impact of Processing on Food Safety. L. S Jackson, M. G. Knize, and J. N. Morgan, eds. Kluwer/Plenum, New York.

35. Podhorniak, L. V., Leake, S., and Schenck, F. J. 1999. Stability of tetracycline antibiotics in raw milk under laboratory storage conditions. J. Food Prot. 62:547-548.

36. Sanderson, H., Ingerslev, F., Brain, R. A. Sorensen, B. H., Bestari, J., Wilson, C. J., Johnson, D. J., and Solomon K. R. 2005. Dissipation of oxytetracycline, chlortetracycline, tetracycline and doxycycline using HPLC-UV and LC/MS/MS under aquatic semi-field microcosm conditions. Chemosphere 60:619-629.

37. Shaath, N. 2005. The chemistry of ultraviolet filters. Pages 217-238 in: Sunscreens: Regulations and Commercial Development, 3rd ed. N. Shaath, ed. Taylor \& Francis, New York.

38. Shepard, D. P., and Zehr, E. I. 1994. Epiphytic persistence of Xanthomonas campestris pv. pruni on peach and plum. Plant Dis. 78:627629.

39. Strickland, T. C., Truman, C. C., and Frauenfeld, B. 2005. Variable rainfall intensity effects on carbon characteristics of eroded sediments from two coastal plain ultisols in Georgia. J. Soil Water Conserv. 60:142-148.

40. Tamez-Guerra, P., Mcguire, M. R., Behle, R. W., Hamm, J. J., Sumner, H. R., and Shasha, B. S 2000. Sunlight persistence and rainfastness of spray-dried formulations of baculovirus isolated from Anagrapha falcifera (Lepidoptera: Noctuidae) J. Econ. Entomol. 93:210-218

41. Vale, F. X. R., Fernandes Filho, E. I., Liberato, J. R., and Zambolim, L. 2001. Quant - a software to quantify plant disease severity. Page 160 in: Proc. 8th Int. Workshop Plant Dis. Epidemiol., Ouro Preto, Brazil.

42. Verma, B., Headley, J. V., and Robarts, R. D. 2007. Behaviour and fate of tetracycline in river and wetland waters on the Canadian Northern Great Plains. J. Environ. Sci. Health 42:109-117.

43. Vicent, A., Armengol, J., and García-Jiménez, J. 2007. Rain fastness and persistence of fungicides for control of Alternaria brown spot of citrus. Plant Dis. 91:393-399.

44. Zaccardelli, M., Malaguti, S., and Bazzi, C. 1998. Biological and epidemiological aspects of Xanthomonas arboricola pv. pruni on peach in Italy. J. Plant Pathol. 80:125-132. 